\title{
COMPUTER AIDED RESTORATION TOOLS TO ASSIST THE CONSERVATION OF AN ANCIENT SCULPTURE. THE COLOSSAL STATUE OF ZEUS ENTHRONED.
}

\author{
F. Di Paola ${ }^{\text {a, }}$, G. Milazzo ${ }^{\text {b }}$ F. Spatafora ${ }^{\mathrm{c}}$ \\ ${ }^{a}$ Department of Architecture, Polytecnic School of Palermo, \\ Viale delle Scienze 90128, Palermo, Italy, francesco.dipaola@unipa.it \\ b Milazzo Restauri S.r.l., Palermo, Italy, milazzorestauri@gmail.com \\ "Regional Archaeological Museum “A. Salinas”, \\ Palermo, Italy, poloarcheologico.pa@ regione.sicilia.it
}

\section{Commission II, WG VI/4}

KEY WORDS: Cultural Heritage, restauration, conservation, 3D modeling, virtual recomposition, 3D printing.

\begin{abstract}
:
The research focuses on the contribution of the integrated application of Computer Aided Restoration digital procedures as a means to guide the integration measure of an artifact, innovating and implementing the traditional investigation methods. The aim of the study was to provide effective geometrical-formal investigation tools in the frame of the conservation work of Zeus enthroned from Soluntum, conserved in the Archaeological Museum "A. Salinas" of Palermo. The paper describes the workflow of the 3D acquisition and graphical modeling with non-invasive digitalization and high information density techniques to assist the conservation of the legs of the throne, especially the integration of the missing part. Thanks to the technique of the digital fabrication it has been reconstruct the two missing parts following the theoretical criteria as: recognisability, compatibility and retractability. This innovative application of 3D digital technologies have showed as the integrated use of the new technology can be a useful tools for improving the conservation of a work of art.
\end{abstract}

\section{INTRODUCTION}

Operative procedures and protocols for the enhancement of scientific survey tools, which employ computerised and automatic procedures, are nowadays well-established. These are being promoted by museum institutions, superintendencies, and authorities specialised in conservation, diagnostics, and restoration of artworks and archaeological finds.

Among the new technologies currently proposed for the application to cultural heritage, the potential of 3D scanning and Digital Fabrication represents a significant example of how distant fields, such as conservation, research, and advanced industry can share a common interest.

Among the possible applications of these technologies, the production of scaled-down copies of art pieces is surely interesting. These can serve a variety of purposes, such as temporary replacement for the original ones which may be on a loan, under ongoing restoration, subject to theft, or to serve as a fruition device for the visually impaired.

Recent events involving damaging and destruction of archaeological sites, pushed experts and scholars to find effective solutions to crimes against historical and artistic world heritage (Llamas, et al., 2016; Arbace, et al., 2013).

To cite a few virtuous initiatives, the Association for Research into Crimes Against Art (ARCA) started a series of actions to fight heinous destructive acts and defend cultural heritage internationally against catastrophic events of natural origin. Italy supports UNESCO with the newly established task force "The Blue Helmets of Culture".

One of the actions with highest priority carried out by the authorities involves the development of digital methodologies for archiving, recording, and restoration of priceless artefacts, following their deterioration or destruction (Gruen, et al., 2003; Lo Presti, et al., 2011).

An emblematic example is the recent reproduction in scale 1:3, through CNC machinery, of the Monumental Arch of Palmyra (Syria) near the Temple of Bel, destroyed in 2015 with explosives and jackhammers by ISIS militia.

An international project, called The Million Image Database, funded by the Institute for Digital Archaeology (IDA) in Oxford made possible the temporary exposition of a 15-meters tall digital copy during the events of the World Heritage Week last April (https://goo.gl/5wfzm4).

The Smithsonian X3D project, is another example of best practice in the field of cultural heritage. The Smithsonian Institution constitutes one of the world's richest establishments, with its 19 museum venues and over 140 affiliate institutions. Its collection includes 137 million artefacts and artworks only partially accessible to visitors, while the rest is stored and available only to scholars, archaeologist, and professionals.

The aforementioned project aims to the digitalisation of the whole collection, creating a database available to a broader public and allowing an integrated documentation, which would be heterogeneous, shareable, and implementable over time (https://goo.gl/WSYgfz).

The traditional way of casting is, in the field of cultural heritage conservation, deemed as an invasive operation. It involves direct physical contact with the artefact, requiring an analysis of the material degradation of the artwork and an in-depth knowledge of the chemical and physical properties of the material used, as well as the damage it may cause.

\footnotetext{
* Corresponding author
} 
Nowadays casting is usually not recommended. In Italy, however, it is permitted under exceptional cases, regulated by the Ministerial Decree of 20th of April, 2015.

Noninvasive experimental use of methodologies and innovative tools has been developed for analytical procedures of geometric dimensional data, restoration, and monitoring (Inzerillo, et.al., 2013).

This work of art is one of the most important archaeological finds of the first half of the XIX century in Sicily. This pseudoacrolithic statue, which combines limestone for the body with white marble for the mask of the face and for the neck, is one of the few examples of large size statue in Sicily. It was discovered fragmented in the ancient city of Soluntum in the 1825, one of the main important archaeological sites in Sicily, not so far from the modern town of Palermo (Sicily).

The following describes the methodology applied to the case study.

\section{MATERIAL AND METHODS}

In the 1826, the neoclassical sculptor Valerio Villareale restored the statue of Zeus joining the fragments and completing the missing parts with stucco reconstructions, succeeding in the difficult task to joining several fragments of the colossal worship statue (Fig. 1).

In the 2014 the statue of Zeus was undergoing a conservation treatment completed in the 2015 with the aim to improve its complex state of conservation that did not allowed to observe any peculiarities of the original polychrome technique of execution.

Zeus is represented as a bearded figure sitting on a throne, in forward position, with both arms raised to the bust. Zeus wears a chiton, almost entirely hidden by an himation, which surround the lower part of the body and turning on the left shoulder and forearm. The head has a big curly hair and the marble face has a low forehead, a pronounced nose, high cheekbones, full lips and big eyes. The right leg is forward and the foot worn a sandal with a fastening decorated with oak leaf, while the left foot is backward and not finished. Booth the feet of the statue are standing on a stool, richly decorated on the front with sophisticated vegetable motif, with sphinx shaped legs.

Only two legs, column shaped, are conserved of the original throne. They are decorated with a high relief depicting three central figures for each leg, considered two candle holders since their discovering.

In the right leg is depicted a warrior, as Ares, crowned by a Winged Victory, on the left, and a female figure attends the coronation at the right, she is dressed with chiton and himation and she is identified as Aphrodite with Eros on the left shoulder.

The left leg of the throne has an high relief with three female figures dressed whit chiton and himation, almost unanimously identified with the Three Graces (Lo Faso, 1831; Ferri, 1941).

The cleaning, performed to remove all the extraneous materials added during the previous restorations, has allowed to study in deep the original appearance of two legs.

It became clear as their fragments were been joined wrongly during the Villareale's restoration, maybe he was inspired by the idea of the candle holders (Fig. 2).

From a theoretical point of view the conservative treatment must aim to give the suitable reading of the work of art.

Thanks to a scientific approach, oriented to respect the original matter of the work of art, each conservative activity was aimed
In our case study, the conservation of the colossal enthroned statue of the god Zeus, the innovative applied technologies had the purpose of creating a 3D collection of data to assist the restoration and conservation.

to investigate and to study the original appearance of the statue and its throne.

A comparative historical-artistic study was undertaken, comparing the result of the observation with several artifacts from the same period. Finally it has been understood the original shape of the legs of the throne, but both the legs had a missed portion unfortunately.

During the conservation workflow a great contribution in terms of knowledge and supporting restoration work was made by the use of the latest generation and noninvasive technologies, called Time Compression Technologies (TCT), such as Reverse Engineering, Virtual Reality and Digital Fabrication.

The 3D models, generated using a high-resolution 3D scanner based on blue light technology, provide an accurate graphic documentation useful for recording the state of conservation of the works of art, just after their conservation (Lo Brutto, et al., 2017).

The models were used to compare hypotheses for the reconstruction of the various fragments, to create a virtual recomposed statue from re-assembled fragments.

The 3D printing technique played a pivotal role to complete the missing parts; it was studied a methodology to enhance the reading of the throne, unknown until now.

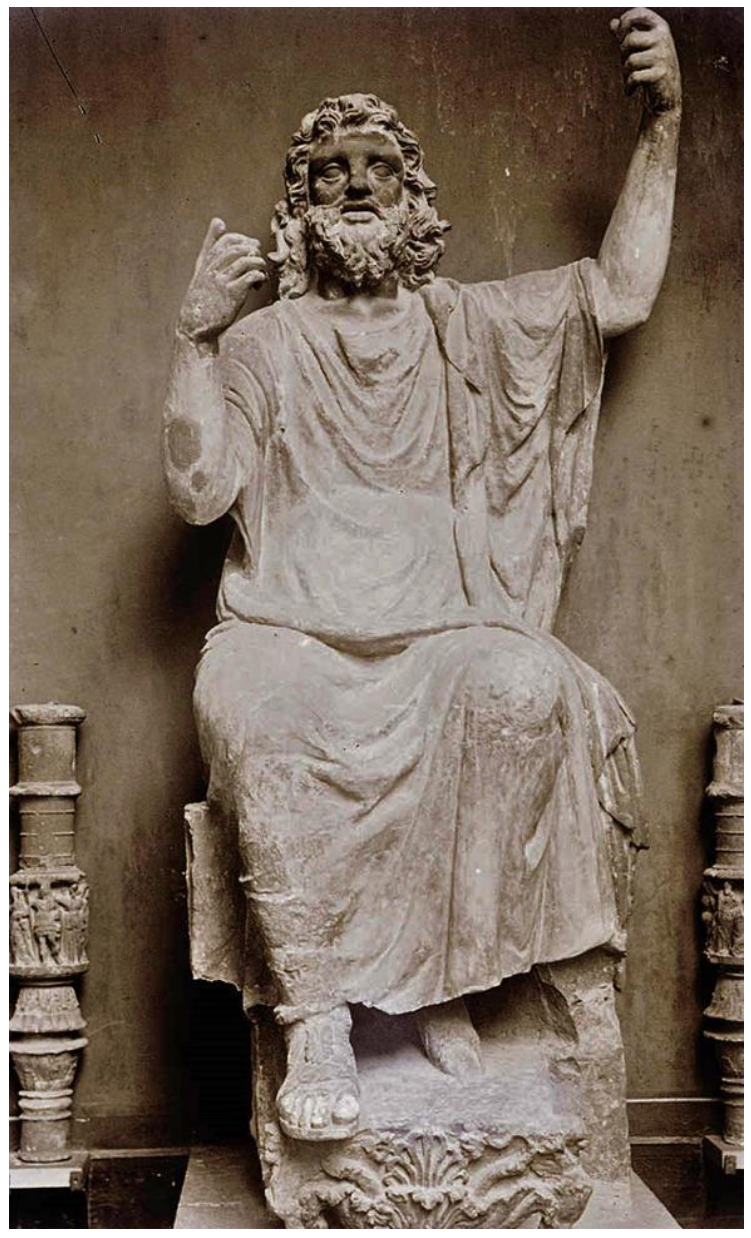

Figure 1. Statue enthroned of the god Zeus from Soluntum, second half of the XIX century

(Archaelogical Museum of Palermo A. Salinas) 


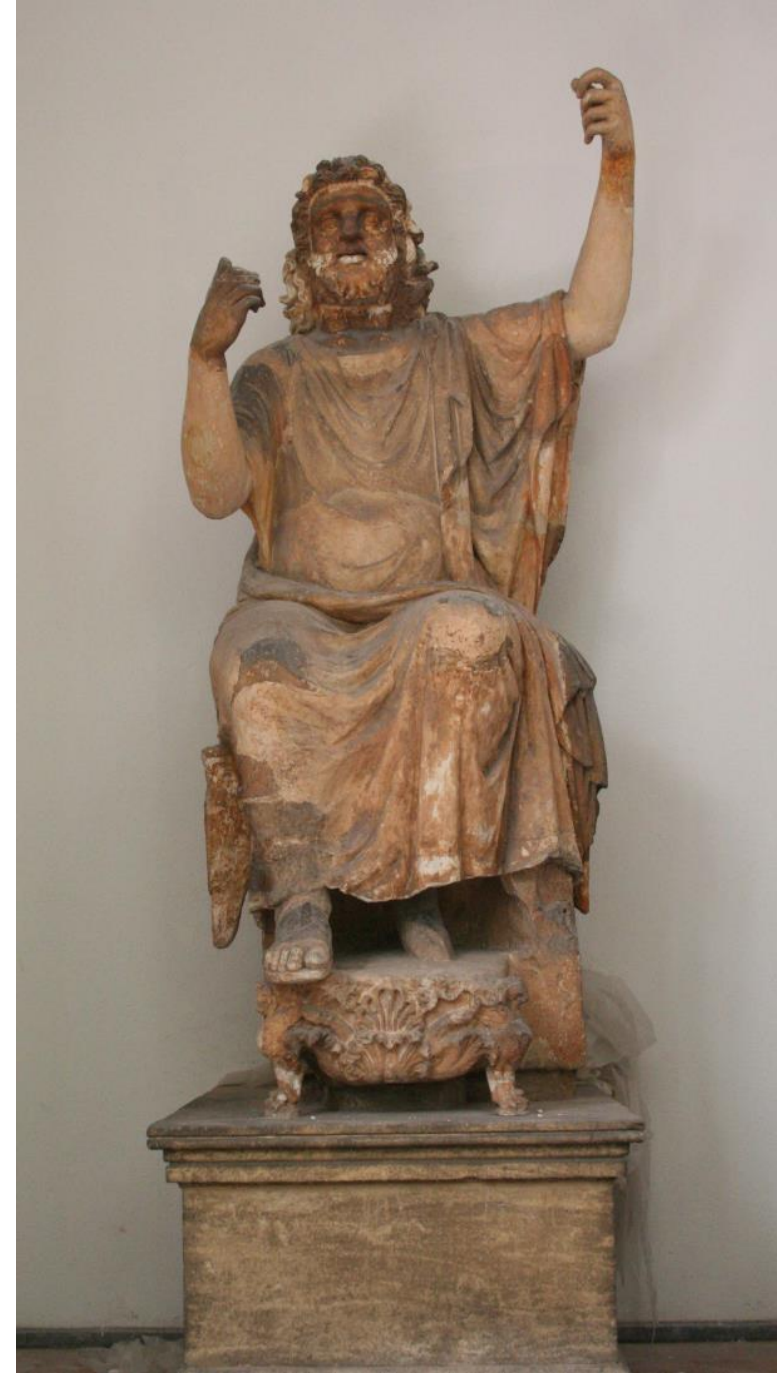

Figure 2. Statue enthroned of the god Zeus from Soluntum, before the conservation,

(Archaelogical Museum of Palermo A. Salinas)

\subsection{Digital acquisition and data-processing}

The process started on physical models is defined as reverse modeling, and the digital resolution up to $0.1 \mathrm{~mm}$ for each object was realized using a 3D portable scanning system with a structured light flash bulb (Artec 3D Scanner_Spider), permitting highly detailed digital models to be produced.

The choice of this technology was greatly determined by the physical characteristics of the object to be scanned, including the size, the complexity of its outer surfaces and the constraints on access/manipulation.

The legs of the throne are high $100 \mathrm{~cm}$ about with a $20 \mathrm{~cm}$ of diameter (Fig. 3).

The campaign of indirect detection was carried out by the team in 5 working days, with the collaboration of the conservator for the handling of the pieces.

The acquisition structured light system is based on the capture of the points that make up the surface of a physical object returning a digital 3D model with a high degree of geometric correspondence to the real object.
The extremely versatile system scans at 8 frames per second; frames are automatically aligned in real-time (it does not require any special markers to be placed on the object being scanned).

The process is functional, rapid, and capable of acquiring almost 1.000 .000 points/s and turned out to be particularly suitable for the geometric dimensional characteristics of the objects.

The structured light system works with a light source projecting a series of light patterns on the object to be scanned (blue LED). The reflected image is captured by cameras, and from the analysis of the distortion of the pattern, the position is evaluated on each point of the surface to be scanned (Alberghina, et al., 2016).
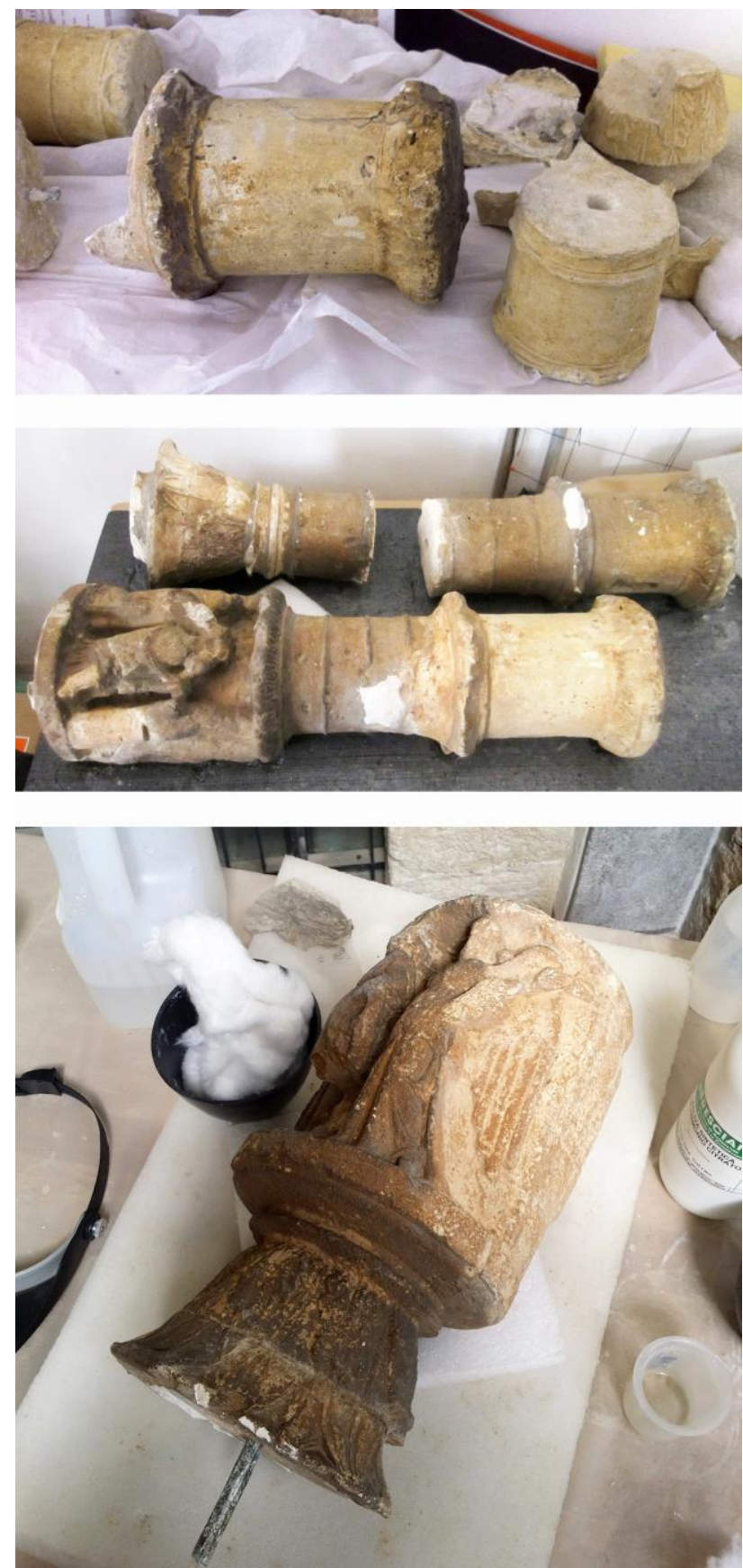

Figure 3. Details of the throne's legs fragment during the conservation measures 
The used tool captures images also (texture resolution $1.3 \mathrm{Mp}$ and image color $24 \mathrm{bpp}$ ).

To obtain a complete 3D model, it is sufficient to move around the object and film it from various angles (angular field of view, $\mathrm{H} \times \mathrm{W}, 30 \times 21 \mathrm{deg}$ ).

Considering the complex forms of scanning objects, the geometry + texture tracker was employed. It allows the registration algorithm to track and align scans using both texture and geometrical features of the object that is being scanned; using a geometry + texture tracker ensures the best possible results.

During the acquisition phase, the optimum working distance is from 0.17 to $0.35 \mathrm{~m}$. If it gets out of distance range or the movement is too abrupt, the management software loses traceability and goes into error.

Although the technical characteristics report alleged irrelevance of the camera angle, it is easy to observe how rays, which are perpendicularly incident and/or not tangent, assure a greater final accuracy.

The related proprietary software (Artec Studio, software for professional 3D scanning and data processing) automatically joins all the acquired frames in a single mesh.

The algorithm, in fact, recognizes the geometry of the object (points clouds processing) and allows the correct alignment of the various captured 3D frames to visualize them in a single model (therefore conserving the reference system), eliminating as much as possible the presence of holes and shadows due to back drafts.

After the scanning and data registration process (the workflow includes the following stages: revising and editing the data, alignment of scans, global data registration, fusion of data into a single 3D model, final editing of the 3D model, and texture mapping), the procedural phases of postprocessing and polygon mesh tessellation were performed through the Leios, mesh editing, and reverse engineering software. This software directly integrates with the Artec Spider $3 D$ scanner with dedicated tools that allow a rapid optimization of point clouds and meshes and full support for textures and huge raw datasets. The software was developed by an Italian company, EGS.

Semiautomatic algorithms, which are able to take into account the surface geometry (curvature, adjacency edges, and density of the polygonal mesh), remove artifacts scans.

The method is the $u v$ mapping that correlates the spatial coordinates of the polygon model (related to the points and mesh vertices) to texture coordinates; in particular, the Artec Studio software uses the atlas texture method (image size: 2048 $\times 2048$ ).

An atlas texture is a large image containing a collection, or "atlas," of sub-images, each of which is a texture for some part of a 3D object. This method cuts the surface into chunks, unfolds, and nests them flat, and fits them into the image of a specified size. The processing takes a long time in relation to the surface detail and the size of the scanning object, but the texture obtained is convenient for manual editing.

The high-quality 3D digital models are responsive to the complexity of the geometric-form of the analyzed objects, and the digital collection reproduces the decorations in organic form really well.

The collected data so far are a great start for deepening the existing knowledge from the archeometric to the conservative point of view.

The geometric survey helps us to evaluate the state of material preservation of the external portions of the object and permits the registration of anomalies and stresses to which the object has been subjected through a systematic program of monitoring (Fig. 4).

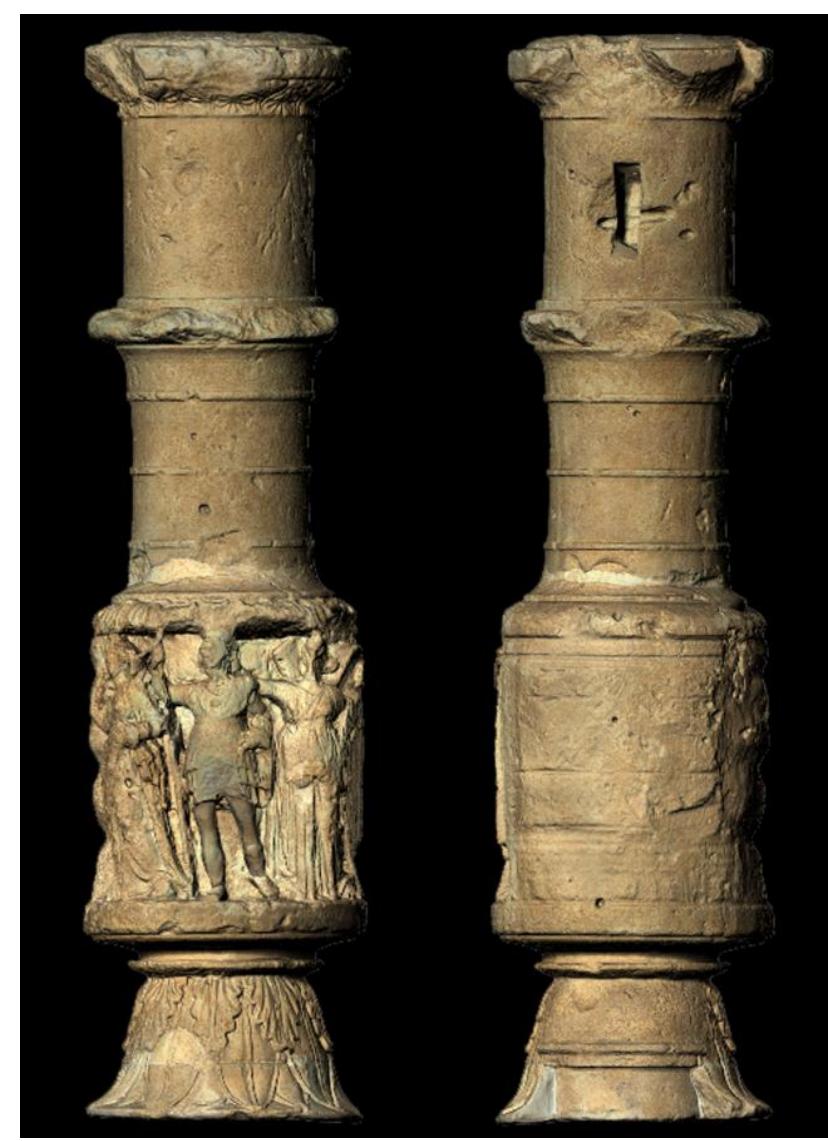

Figure 4. The 3D digital model of a leg of the throne

\subsection{Digital anastylosis and fabrication of missing parts}

Digital fabrication techniques allow the casting of physical objects directly from 3D geometries through CNC machinery. The reproduction of missing parts involves a rapid prototyping (RP) or 3D printing process, by means of a FDM (Fused Deposition Modeling) additive technique.

This involves the extrusion of plastic material, usually ABS or PLA. The plastic string goes through a heated pipe and is smelted immediately before extrusion. It solidifies right after being laid down, adhering to the rest of the material (the thermoplastic polymer employed for $3 \mathrm{D}$ printing is polylactic acid or PLA, obtained from corn fermentation).

A procedure was followed from the preparation of the digital model to the final execution, which can be divided into a logical sequence ranging from the verification of the model to the actual printing phase (Pena Serna, et al., 2011; Menna, et. al., 2016) (Fig. 5).

2.2.1 CAD model verification: The CAD model, obtained as the algorithm's output, needed to be verified beforehand.

In the model are allowed no manifold edges (i.e. belonging to more than two faces), which would result in self-intersections of the final object, or open edges.

Finally, each polygonal face of the resulting geometry must present its perpendicular vector facing outward with respect to the solid. 


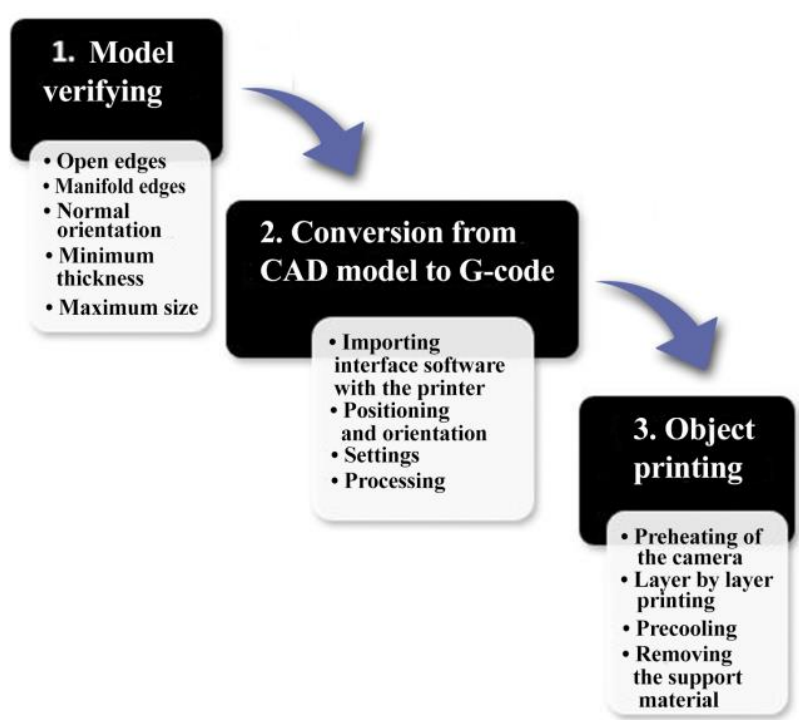

Figure 5. The workflow describes the procedure from the preparation of the digital model to the final execution

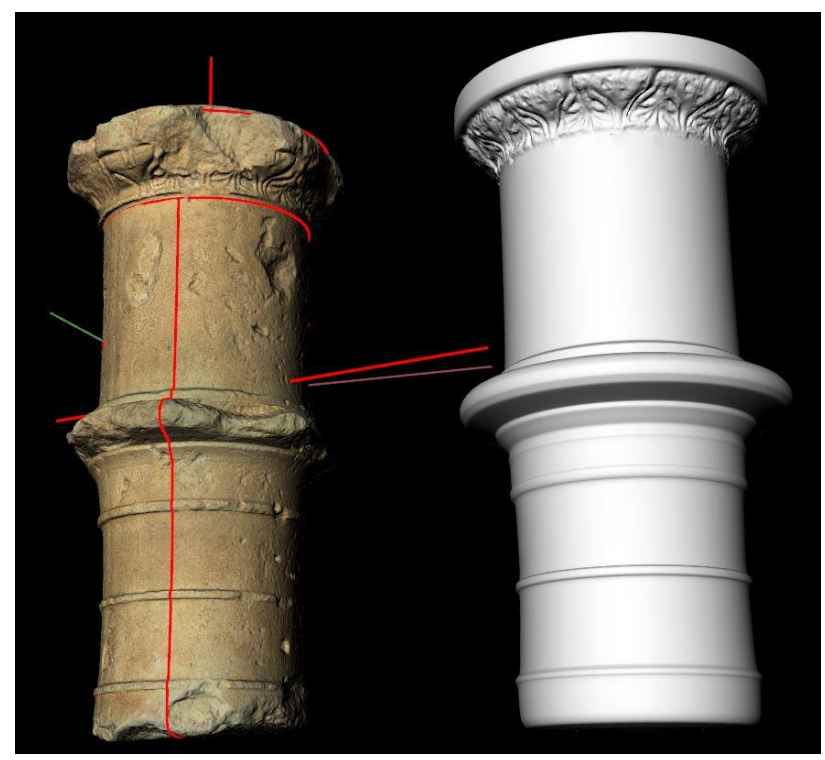

Figure 6. Virtual anastylosis of missing parts

Dimensional limitations, such as minimum thickness and maximum size of the object, must be managed according to material and type of 3D printing technique employed (Fig. 6).

2.2.2 CAD to G-Code model conversion: Once verification and correction of the model was completed, it was possible to proceed with the object prototyping.

The 3D model was then exported as .stl (Standard Triangulation Language) format from Rhinoceros, thus allowing it to be read by printing software.

The file conversion to .stl format discretizes the object surface into triangles and stores the data in spatial coordinates $\{\mathrm{x}, \mathrm{y}, \mathrm{z}\}$ and vectors, representing triangle vertices and face normal respectively.

The file thus obtained was then imported into Cura (release 15.04.6, developed by UltiMaker). This allowed to set printing parameters and define critical undercut or overhang areas where supporting material will be laid, ensuring stability during production phases.

The 3D printer used was the Delta 2040, by WASProject, equipped with: a heated extruder mounted onto a delta robottype structure; a working surface; a coil rack; a heated chamber, allowing maximum printing size of $200 \times 200 \times 400 \mathrm{~mm}$.

The material was deposited by the printing head layer by layer, defined by a slicing software starting from the 3D file. It was then possible to build an object of any shape or type within the technology's limit (Lu, 2014; Fantini, 2008).

Before sending the file to the printing device, it is necessary to orient and move the scaled object inside the printing area.

Since the given geometry showed no preferential supporting planes, a position capable to keep a static balance during the entire printing process was chosen. The amount of supporting material needed for the chosen configuration, which would be removed at the end, was then set.

The most interesting printing parameters being set during the following phase are layer resolution and material density. These have a crucial relevance towards the duration of the printing process, its cost, and the quality of the final result.

Layer resolution determines the thickness along the $z$ direction of the progressively deposited layers.

In this case it was set to $0.25 \mathrm{~mm}$.

Material density sets how much material is laid along the $x y$ plane, thus determining the porosity of the material.

The software then divides the model in a sequence of stacked layers (an operation called slicing) and defines the sections where support material will be needed (Figs. 7-8).

The whole operation determines the creation of a G-Code, consisting of an ordered sequence of spatial coordinates which define the path of the extruder during the $3 \mathrm{D}$ printing phase (Table 9).

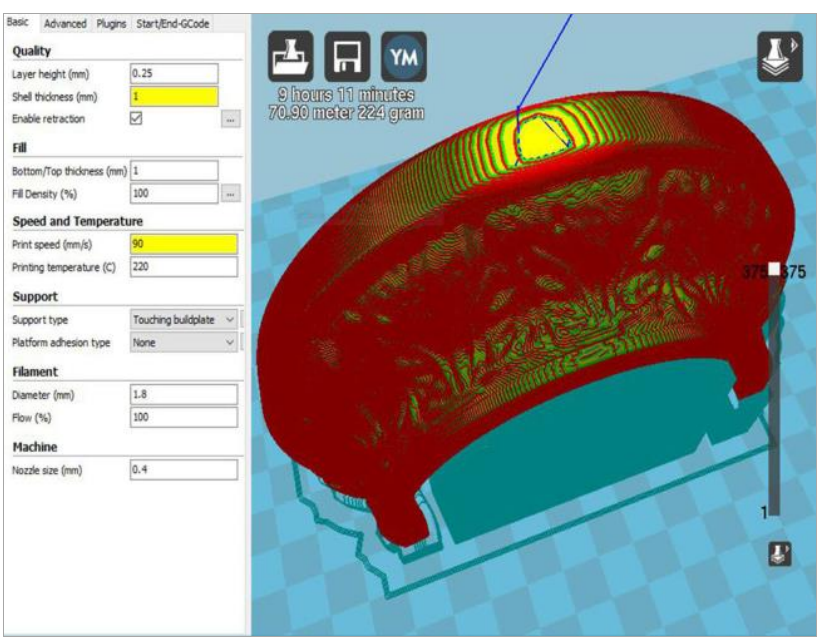

Figure 7. The creation of G-Code file and print phase of object

2.2.3 Object printing: Once the G-Code elaboration phase has ended, information is sent to the printing device.

Before the extrusion nozzle begins the deposit of the material, the printing chamber is heated up for 30 minutes to avoid shrinking or deformation of PLA, which can reach temperatures of up to $220{ }^{\circ} \mathrm{C}$ during the extrusion phase.

The printing process continues layer by layer until the desired object has been completed, taking a variable amount of time according to the model complexity.

The chamber is then gradually cooled down until it reaches room temperature.

Finally, the supporting material is mechanically removed. 

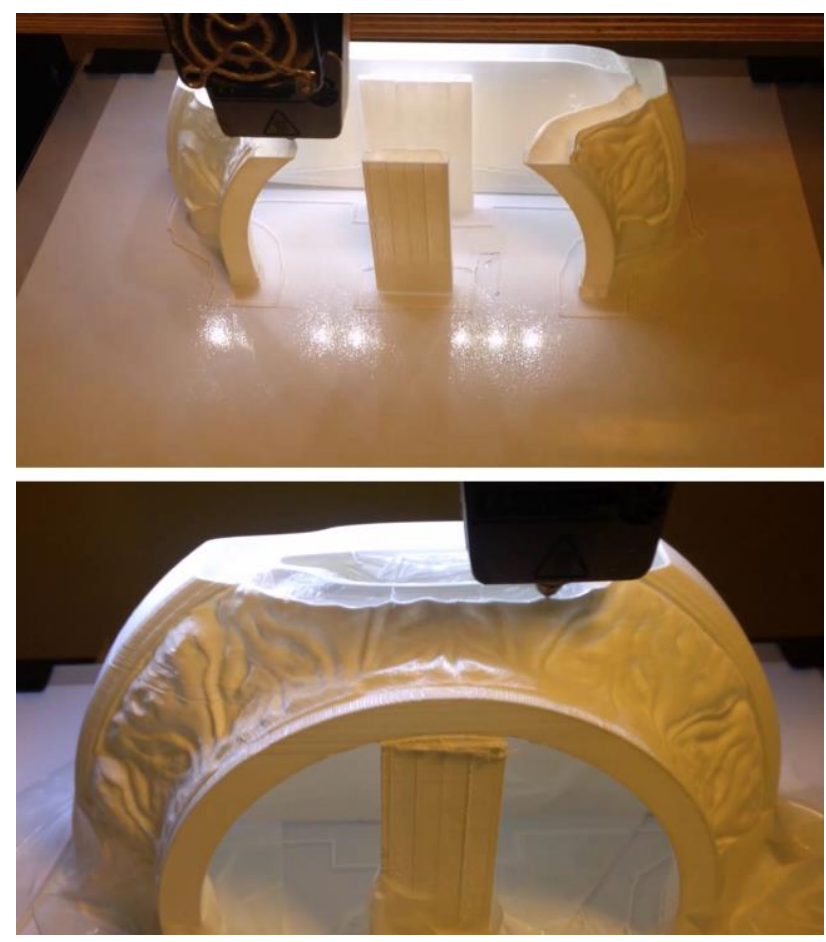

Figure 8 . Two different steps during the printing phase

\begin{tabular}{|c|c|}
\hline Machine Setting & $\begin{array}{c}\text { Basic/Advanced } \\
\text { parameters }\end{array}$ \\
\hline Layer height & $0,25 \mathrm{~mm}$ \\
\hline Shell thickness & $1 \mathrm{~mm}$ \\
\hline Top/bottom thickness & $1 \mathrm{~mm}$ \\
\hline Fill Density & $100 \%$ \\
\hline Printing temperature & $210^{\circ} \mathrm{C}$ \\
\hline Build Plate temperature & $50^{\circ} \mathrm{C}$ \\
\hline Diameter & $1,8 \mathrm{~mm}$ \\
\hline Flow & $100 \%$ \\
\hline Enable retraction & active \\
\hline Print speed & $90 \mathrm{~mm} / \mathrm{s}$ \\
\hline Travel speed & $120 \mathrm{~mm} / \mathrm{s}$ \\
\hline
\end{tabular}

Table 9. Setting print parameters

\section{CONCLUSIONS}

The conservation of the statue enthroned of god Zeus, conserved in the Archaeological Museum of Palermo, have showed as the application of $3 \mathrm{D}$ digital technologies is a useful tool for the conservation of the artifacts. This innovative technologies is strongly valuable to carry out the integration of lacks and missing parts, when is possible to recognize their shape.

The high reliability of this tool guarantee to obtain a copy whit the same proportion of the original one, not easy with the traditional casting techniques.

The exact model obtained by printing, it can be made with different materials chosen on the basis of the environmental condition (indoor or outdoor exposition), guaranteeing the recognisability of the new portions from the originals (Fig. 10).
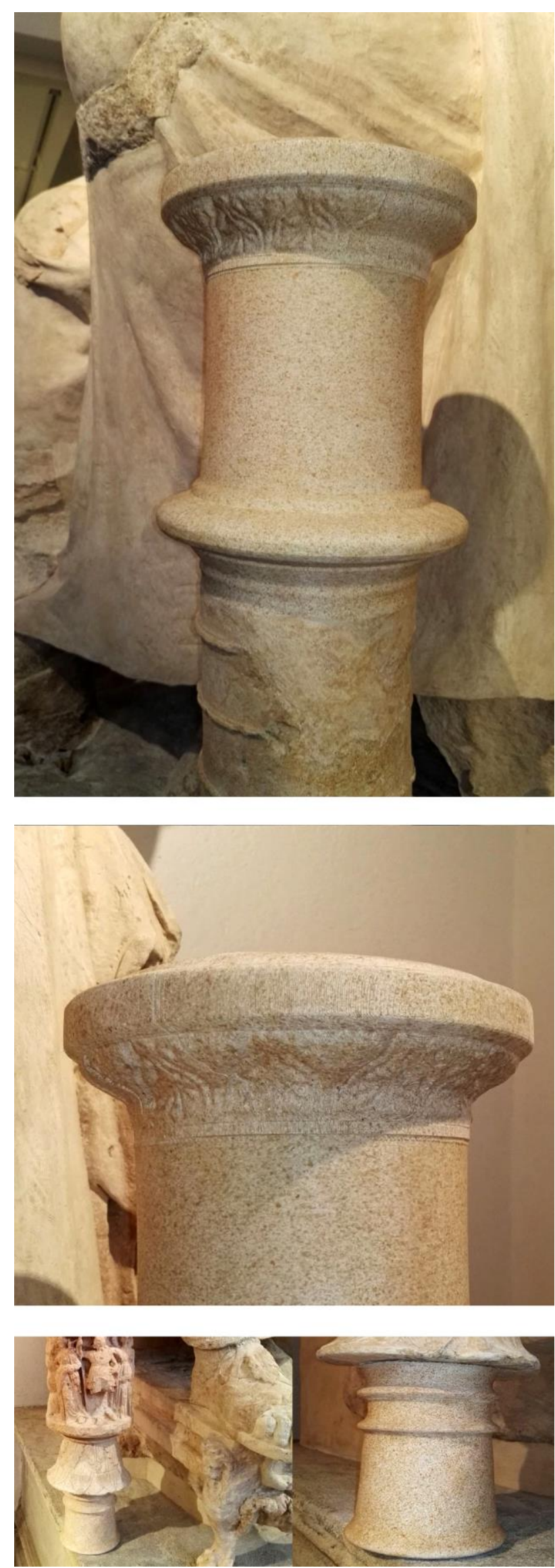

Figure 10. Integration of the printed portions with the work of art. 
This kind of integration, carried out with this methodologies, permits a proper valorization of the work of art permitting to read the artifacts in its authenticity, without the disturbance of the missing parts.

Moreover the integration, with this scientific method, satisfy the conservation methodological criteria as the reversibility, recognisability and compatibility of the printed portion avoiding future risks for the artifact. The printed portions can always be removed easily and separated by the work of art, in according with the reversibility principle.

The use of the 3D technologies allows to acquire the morphological data of the artifacts surface, documenting the state of conservation in that time and favoring the digital reproduction of the work of arts on different communication tools. It is clear enough the great potentiality of the $3 \mathrm{D}$ applications in the conservation field (Neumuieller, 2014).

This relative low cost technology allows to work with high scientific and rigorous approach, with a great saving of the production times and costs.

The application, in sequence of the acquisition data, digital modeling and 3D printing, permit to elaborate hypothesis and suggestions, hardly obtainable with other applications, enhancing the field of the innovative 3D applications from the philological to the virtual conservation (Fig. 11).

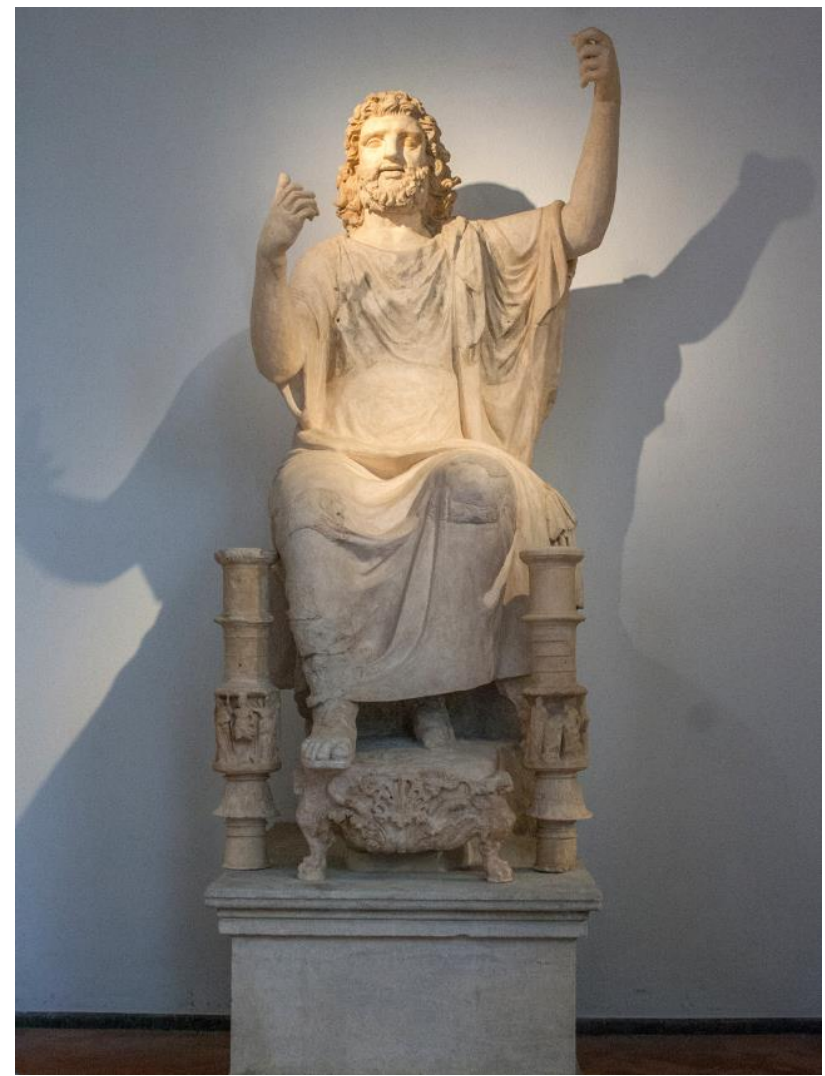

Figure 11. Statue enthroned of the god Zeus after the conservation and the new assembling of the throne's legs, Archaelogical Museum of Palermo A. Salinas

\section{ACKNOWLEDGEMENTS}

Thanks to Claudio Simonetti e Jessica Longo of the DesignEasy Laboratory, for support during the digital fabrication phases.

\section{REFERENCES}

Alberghina, M., Alberghina, F., Allegra, D., Di Paola, F., Maniscalco, L., Milazzo, G., et al., 2016. Integrated threedimensional models for noninvasive monitoring and valorization of the Morgantina silver treasure (Sicily). In Journal of Electronic Imaging (JEI), 26(1), 1-14.

Arbace, L., Sonnino, E., Callieri, M., Dellepiane, M., Fabbri, M., Idelson, A.I. and Scopigno, R., 2013. Innovative uses of 3D digital technologies to assist the restoration of a fragmented terracotta statue, in Journal of Cultural Heritage, vol. 14 (4), pp. 332-345.

Fantini, M., De Crescenzio, F., Persiani, F., Benazzi, S., Gruppioni, G., 2008. 3D restitution, restoration and prototyping of a medieval damaged skull. In Rapid Prototyping Journal 14, pp. 318-324.

Ferri, S., Il problema archeologico di Solunto, 1941, in Le Arti, n. 4, Vol. 1, pp. 250-258.

Gruen, A., Remondino, F., Zhang, L., 2003. Image-based Automated Reconstruction of the Great Buddha of Bamiyan, Afghanistan, Workshop "Comput. Vis. Pattern Recognit”.

Inzerillo, L., Santagati, C., Di Paola, F., 2013. Image-based modeling techniques for architectural heritage 3D digitalization: limits and potentialities, in International Archives of the Photogrammetry, Remote Sensing and Spatial Information Sciences, XL-5(W2): pp. 550-560.

Llamas, J. Lerones, P.M., Zalama, E., Gómez-García-Bermejo, J. 2016. Applying Deep Learning Techniques to Cultural Heritage Images Within the Inception Project. EuroMed 2016: "Digital Heritage. Progress in Cultural Heritage: Documentation, Preservation, and Protection", pp. 25-32, Nicosia, Cyprus, October 31-November 5.

\section{Lo Faso, D., 1831. Cenni sugli avanzi di Solunto, Palermo.}

Lo Brutto, M., Dardanelli, G., Ebolese, D., Milazzo, G., Pipitone, C. and Sciortino, R., 2017. The main portal of the Cathedral of Monreale: first geometric analysis and interpretive assessment of architectural features in The international archives of the photogrammetry, remote sensing and spatial information sciences, XLII-5/W1(XLII-5/W1), 381-387.

Lo Presti, S., Di Paola, F., Mineo, S., 2011. Artificial stone in architecture: new techniques of intervention in the Utveggio Castle in Palermo, in Conservation Science in Cultural Heritage, Issue n. 11, pp. 195-217, DOI: 10.6092/issn.19739494/2698.

Lu, L., Sharf, A., Zhao, H., Wei, Y., Fan, Q., Chen, X., Savoye, Y., Tu, C., Cohen-Or, D. and Chen, B., 2014. Build-to-last: Strength to weight 3D printed objects. In ACM Transactions on Graphics (Proc. SIGGRAPH), 33, 4, August, 97:1- 97:10.

Menna, F., Nocerino, E., Remondino, F., Dellepiane, M., Callieri, R., Scopigno, R., 2016. 3D digitization of an heritage masterpiece - A critical analysis on quality assessment, in International Archives of the Photogrammetry, Remote Sensing and Spatial Information Sciences, Volume XLI-B5, 2016, XXIII ISPRS Congress, (12-19 July 2016), Prague, Czech Republic. 
Neumüeller, M., Reichinger, A., Rist, F., Kern, C., 2014. 3D printing for cultural heritage: Preservation, accessibility, research and education. In $3 D$ Research Challenges in Cultural Heritage, Ioannides M., Quak E., (Eds.), vol. 8355 of Lecture Notes in Computer Science. Springer Berlin Heidelberg, 2014, pp. 119-134.

Pena Serna, S., Scopigno, R. et al, 2011. 3D-centered media linking and semantic enrichment through integrated searching, browsing, viewing and annotating, Proc. of EG VAST: International symposium on virtual reality, archaeology and intelligent cultural heritage, pp. 89-96.

Scopigno, R., Cicogni, P., Pietroni, N., Callieri, M. and Dellepiane, M., 2017. Digital fabrication technique for Cultural Heritage: a survey, in Computer Graphics Forum, V. 36, Issue 1, pp. 6-21. 